\title{
Measurement of the fiber stress distribution during pull-out test by means of micro-Raman spectroscopy and FEM analysis
}

\author{
K. Tanaka ${ }^{1}$, K. Minoshima ${ }^{2}$ \& H. Yamada ${ }^{3}$ \\ ${ }^{1}$ Department of Mechanical Engineering, Doshisha University, Japan \\ ${ }^{2}$ Department of Mechanical Engineering, Osaka University, Japan \\ ${ }^{3}$ Department of Mechanical Engineering, Kyoto University, Japan
}

\begin{abstract}
A single-fiber pull-out model composite for an aramid/epoxy system was specially designed to measure the stress distribution of the aramid fiber embedded in the matrix using micro-Raman spectroscopy. The stress transfer length of the fiber obtained was about $400-500 \mu \mathrm{m}$, which was equal to the result of FEM analysis. Just after the initiation and propagation of the fiber/matrix interfacial debonding, the fiber was broken, and the fiber in the matrix had the axial tensile residual stress. The tensile residual fiber axial stress showed the maximum at around the tip of the interfacial debonding. The stress was reduced and became almost equal to zero after being immersed in deionized water at $80^{\circ} \mathrm{C}$ for $44 \mathrm{~h}$. This behavior agreed with the result of FEM analysis, in which the friction coefficient was introduced in the fiber/matrix interface.

Keywords: interfacial properties, micro-Raman spectroscopy, pull-out test, aramid fiber, friction.
\end{abstract}

\section{Introduction}

Investigation of the fracture strength and fracture mechanism of the fiber/matrix interface is extremely important, because the mechanical properties of the fiber reinforced composites depend strongly not only on the properties of the fibers and the matrix but also on the fiber/matrix interfacial ones. We carried out the single fiber pull-out tests to evaluate the influence of water absorption on the interfacial properties of aramid/epoxy composite (Tanaka et al. [1]). In this 
study, however, the pull-out load, at which the unstable crack propagated through the total embedded fiber length, was used for the measure of the interfacial strength and the stress distribution along the fiber in the matrix was not clarified. Moreover for the study of interfacial crack propagation under fatigue loading, it is extremely important to understand the stress distribution along the fiber close to the crack tip (Minoshima et al. [2]).

Raman spectroscopy is a new technique to directly measure the strain or stress distribution along the fiber embedded in a matrix (e.g. Galiotis et al. [3], Patrikis et al. [4], Cervenka et al. [5]). In this work, a single-fiber pull-out model composite for an aramid/epoxy system was specially designed and Raman spectroscopy was used to clarify the difference of stress distribution along the fiber before and after the interfacial debonding.

\section{Experimental procedure and FEM analysis}

\subsection{Specimen preparation and experimental procedure}

The technique to measure the stress of the fiber using laser Raman spectroscopy is based on the fact that the Raman frequencies are strain (stress) dependent. Therefore, using the calibration curves of the peak wavenumber of Raman spectrum vs. stress of a fiber, the measured Raman peak wavenumber can be converted to an axial stress. In this investigation, the Raman spectra were obtained by means of a laser Raman micro spectrometer (Japan Spectroscopic Co. Ltd, NRS-2000). The 514.5nm line of an argon-ion laser was used and the laser beam was focused to a $1.5 \mu \mathrm{m}$ spot on the fiber by an optical microscope.

The aramid fiber used for single fiber tensile tests was Kevlar 49 manufactured by Du Pont, USA. The fiber had an average diameter of $12 \mu \mathrm{m}$. Specimens were prepared by following the recommended testing procedure as

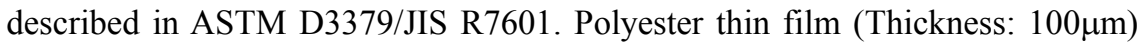
was used for a tab and a single fiber was glued to it, giving a gauge length of 12 $\mathrm{mm}$, as illustrated in fig.1. Quasistatic tensile tests were carried out using a tensile testing machine with a load cell of $1 \mathrm{~N}$ Capacity, which can be installed in the laser Raman micro spectrometer. After chucking a specimen, the tab was cut and the load was applied to the fiber.

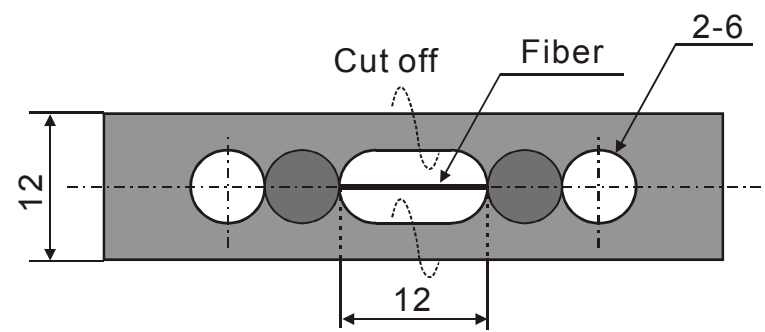

Figure 1: $\quad$ Single fiber tensile test specimen. All dimensions are in $\mathrm{mm}$. 
The specimen construction for a single fiber pull-out specimen is shown in fig.2. An epoxy resin, Epikote 828 and curing agent Epicure Z (Japan Epoxy Resins Co. Ltd.) were used in 5:1 weight ratio. The resin was put on the center of the tab with a fiber, as illustrated in fig.2(a). Specimens were placed in an oven for two hours at $80^{\circ} \mathrm{C}$ and then for two hours at $150^{\circ} \mathrm{C}$. The epoxy resin was remaining on the tab after curing and the fiber was embedded in the matrix between A and B (fig.2(b)). Pull-out tests were performed using a tensile testing machine in the laser Raman micro spectrometer. Raman spectrum was measured along the fiber for both the embedded fiber and the free fiber at several stress levels, as shown in fig.3. In this study the stress of the fiber adopted was the nominal stress, which was calculated from the value of the load cell.

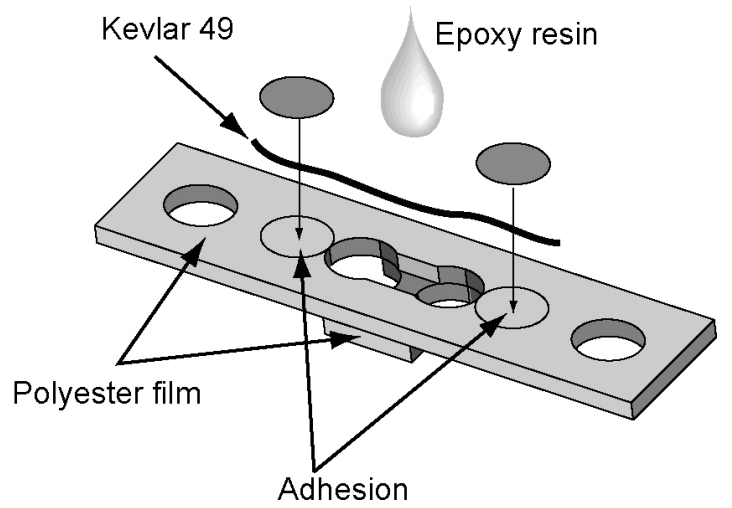

(a) Specimen construction.

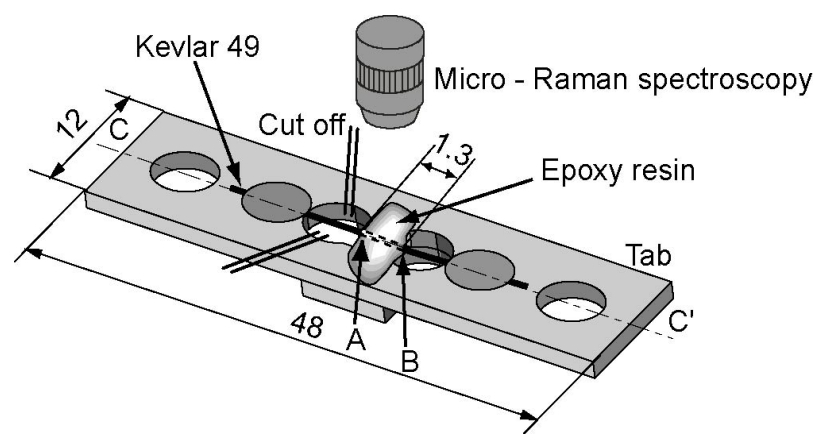

(b) Shape and dimensions of pull-out specimen. All dimensions are in $\mathrm{mm}$.

Figure 2: Single fiber pull-out specimen.

\subsection{FEM analysis}

FEM analysis was conducted using the commercial code ANSYS to estimate the stress distribution during the pull-out test and after fiber/matrix interfacial debonding. Specimen was simplified to the model shown in fig.4(a) and analysis 
was conducted using $2 \mathrm{D}$ model without and with the interfacial debonding of $200 \mu \mathrm{m}$ in length (fig.4(b)). For FEM analysis, thermal expansion during specimen preparation, friction at the fiber/matrix interface and swelling expansion of resin was taken into account. Mechanical properties used in this analysis are shown in table 1 (Hull and Clyne [6], [7], Kawabata et al. [8]). Friction coefficient $(\mu)$ and maximum friction stress $\left(\tau_{\max }\right)$ at the interface were calculated from the result of the previous study [1]. $\mu=0.6$ and $\tau_{\max }=11.9 \mathrm{MPa}$ were obtained and used in the analysis. Swelling of the resin was set at $0.6 \%$ [1] and the swelling of the fiber was neglected.

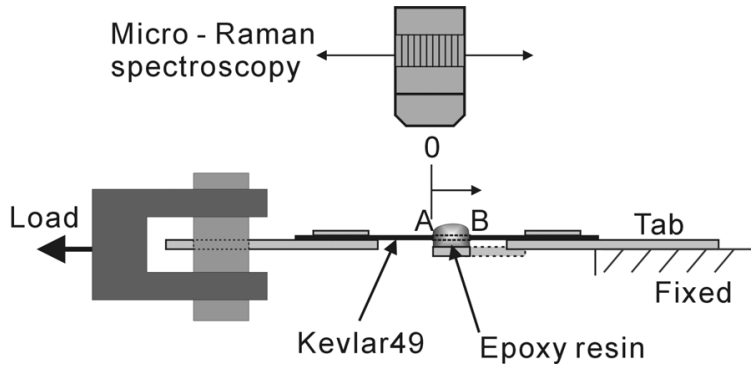

Figure 3: Schematic drawing of the pull-out test procedure (C-C' cross section of fig.2).

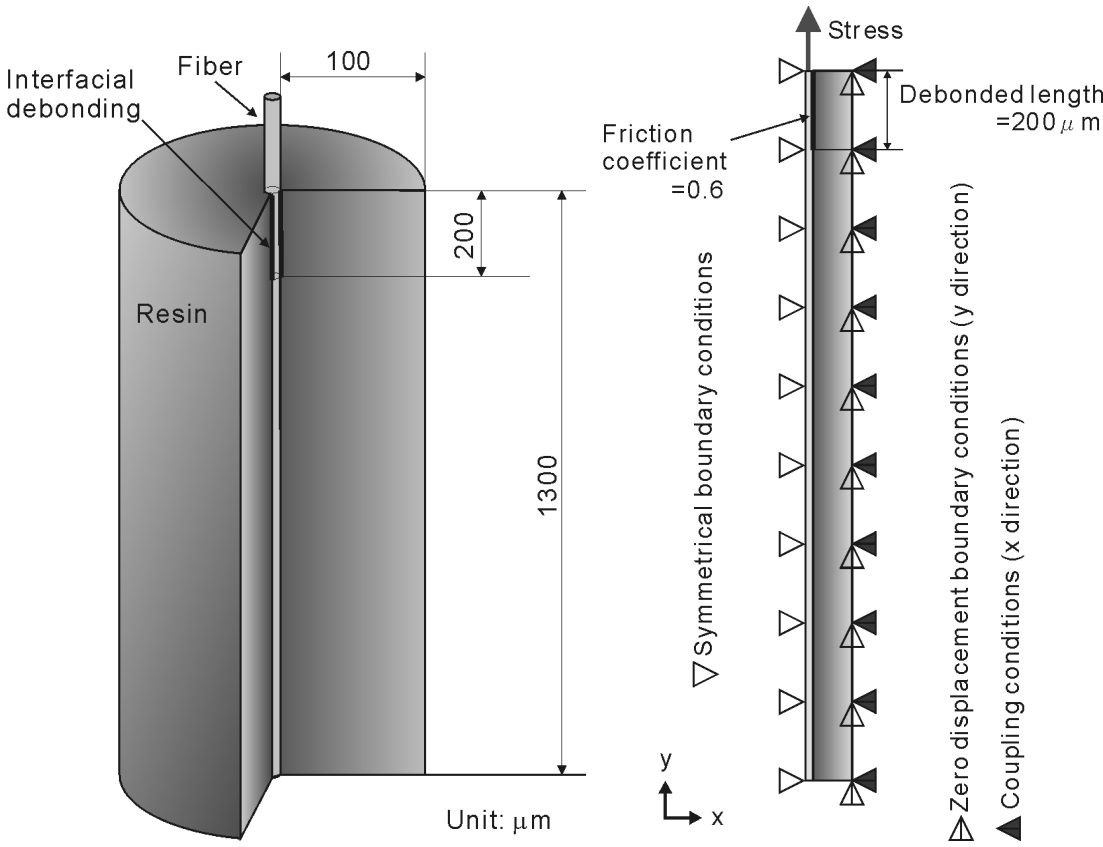

$\begin{array}{ll}\text { (a) Model of the specimen. } & \text { (b) } 2 \mathrm{D} \text { model with boundary conditions. }\end{array}$

Figure 4: $\quad$ FEM model with interfacial debonding. 
Table 1: $\quad$ Mechanical properties of the fiber and resin [6-8]: (a) Epoxy resin (Epikote828 + Epicure Z), (b) Fiber (Kevlar 49).

(a)

\begin{tabular}{|l|c|}
\hline Young's modulus & $2.48 \mathrm{GPa}$ \\
\hline Poisson's ratio & 0.4 \\
\hline Coefficient of thermal expansion & $60 \times 10^{-6}{ }^{\circ} \mathrm{C}^{-1}$ \\
\hline
\end{tabular}

(b)

\begin{tabular}{|l|c|c|}
\hline \multirow{2}{*}{ Young's modulus } & $\mathrm{E}_{\mathrm{L}}$ & $129.6 \mathrm{GPa}$ \\
\cline { 2 - 3 } & $\mathrm{E}_{\mathrm{T}}$ & $2.49 \mathrm{GPa}$ \\
\hline \multirow{2}{*}{ Poisson's ratio } & $v_{\mathrm{LT}}$ & 0.62 \\
\cline { 2 - 3 } & $v_{\mathrm{TT}}$ & 0.31 \\
\hline \multirow{2}{*}{ Coefficient of thermal expansion } & $\mathrm{L}$ & $-2 \times 10^{-6}{ }^{\circ} \mathrm{C}^{-1}$ \\
\cline { 2 - 3 } & $\mathrm{T}$ & $59 \times 10^{-6}{ }^{\circ} \mathrm{C}^{-1}$ \\
\hline
\end{tabular}

L: longitudinal direction, T: Radius direction.

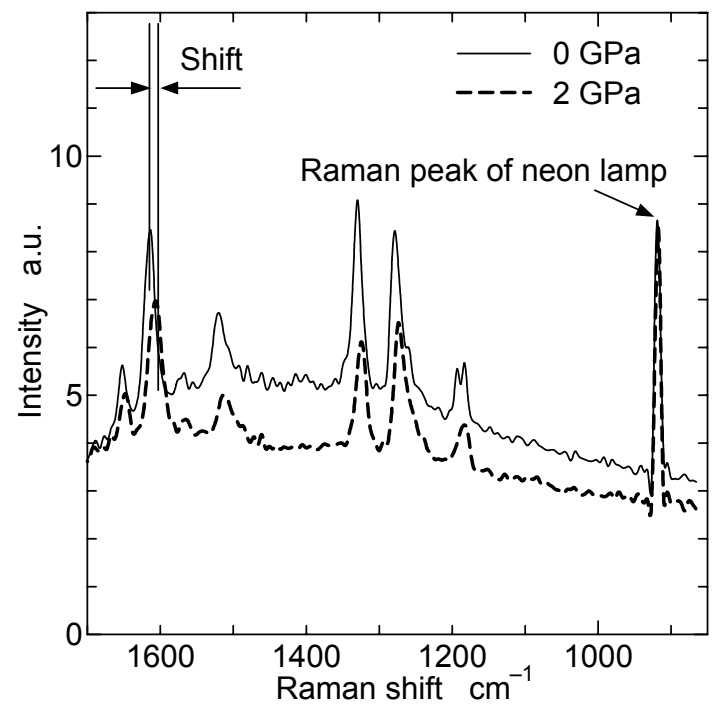

Figure 5: $\quad$ Examples of the Raman spectrum of Kevlar 49.

\section{Results and discussion}

Raman spectra of a Kevlar 49 single fiber without loading and with loading of 2 $\mathrm{GPa}$ tensile stress are shown in fig.5. The increase in tensile stress resulted in a clear shift of the spectrum to a lower wavenumber. In this study, a strong band 
around $1615 \mathrm{~cm}^{-1}$, which corresponds mainly to the phenyl ring/C-C stretching (Parthenios et al. [9]), was used to evaluate the stress.

The influence of the applied load on the Raman peak position for a Kevlar 49 single fiber is shown in fig.6. Four specimens were tested and each result was shown by the same symbol. A linear decrease in the Raman peak position with stress was found, irrespective of the specimens. Therefore, the liner regression line for the measured results shown in the figure was used to estimate the tensile stress of the embedded fiber. The maximum difference between the liner regression line and the tensile stress of each specimen was $0.1 \mathrm{GPa}$. Therefore our system achieves the stress measurement accuracy of $0.1 \mathrm{GPa}$.

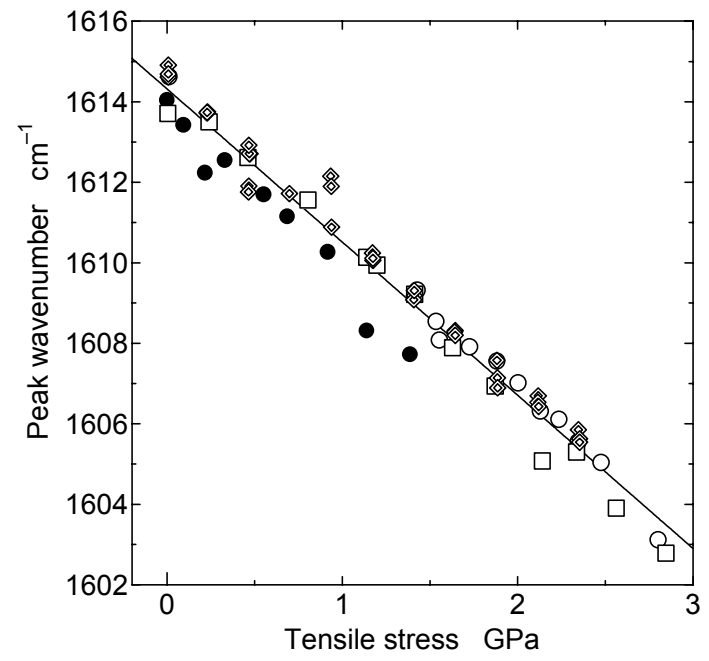

Figure 6: Relationship between tensile stress of Kevlar 49 single fiber and peak wavenumber.

The stress distribution of the axial tensile stress of the fiber during the pullout test was shown in fig.7 with the result of FEM analysis. The applied nominal stress to the fiber is also plotted in the figure. The origin point of the distance along the fiber is the meniscus point from which the fiber was embedded in the epoxy matrix. The fiber at the positive value of the distance along fiber was embedded in the resin matrix, whereas the fiber at the negative value corresponded to the unembedded free fiber. The stress distribution was measured when the applied stress was $0,0.47,0.94,1.41,1.89$ and $2.36 \mathrm{GPa}$. The stress of the embedded fiber decreased gradually along the fiber from the meniscus point, which means that the stress was transferred from the fiber to the matrix. Considering from the fact that the fiber axial stress at the distance of $400 \mu \mathrm{m}$ and that of $500 \mu \mathrm{m}$ were almost equal, the stress transfer length was about 400-500 $\mu \mathrm{m}$ for the Aramid/epoxy system adopted in our study. This behavior is agreed with the result of FEM analysis. 


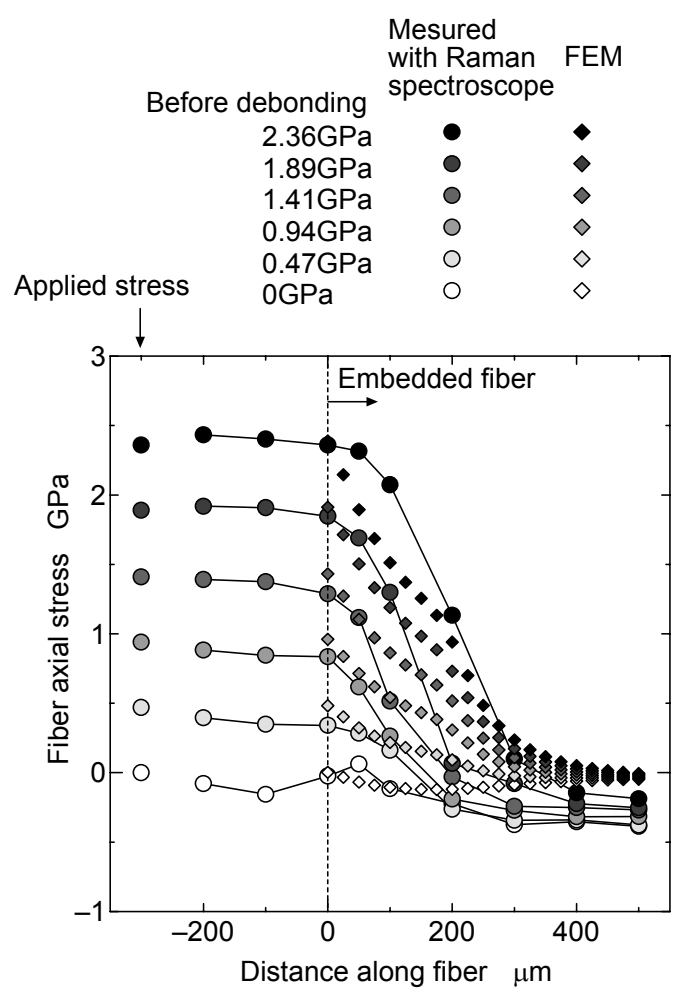

Figure 7: Fiber axial stress along the fiber before debonding with the results of FEM analysis.

When the applied stress was increased to $2.65 \mathrm{GPa}$, the fiber/matrix interfacial debonding was initiated and propagated, and at the same time the fiber was fractured. After this interfacial debonding, the stress distribution in the resin was again measured. The stress distribution after the fiber/matrix interfacial debonding differed from that before the debonding, which is shown in fig.8. Although external stress was not applied to the fiber because of fiber fracture, the fiber axial stress in the debonded region had the residual tensile stress and had the maximum at the distance of around $200 \mu \mathrm{m}$. The position of the interfacial crack tip was $180 \mu \mathrm{m}$, which was confirmed after Raman measurement by using optical microscope. This crack tip was located almost at the position of maximum residual stress. This residual stress was considered to be caused by the holding of the previous stress by the fiber/matrix interfacial friction acting on the debonded interface. This speculation was supported by the fact that the friction stress plays an important role in the propagation of the fiber/matrix interfacial debonding and the propagation rate of interfacial debonding slowed down and retarded when the a constant fatigue load was applied to the specimen [2].

After debonding, this specimen was kept in dry air (relative humidity: $25 \%$ ) for $144 \mathrm{~h}$ and after that it was immersed in deionized water at $80{ }^{\circ} \mathrm{C}$ for $44 \mathrm{~h}$. 
Raman spectrum were measured during and after these conditioning. Figure 8 shows the influence of conditioning in dry air and successive hot water on the fiber axial stress along the fiber after debonding. Analytical results are also plotted in the figure. The conditioning in dry air did not affect so much on the stress distribution, but after immersed in hot water the residual stress decreased to almost $0 \mathrm{GPa}$. The absolute values obtained by the FEM analysis were not equal to the experimental results, but the behavior that the residual stress showed the maximum stress at around the crack tip of interfacial debonding and it decreased by conditioning in hot water agreed with the result of experiment.

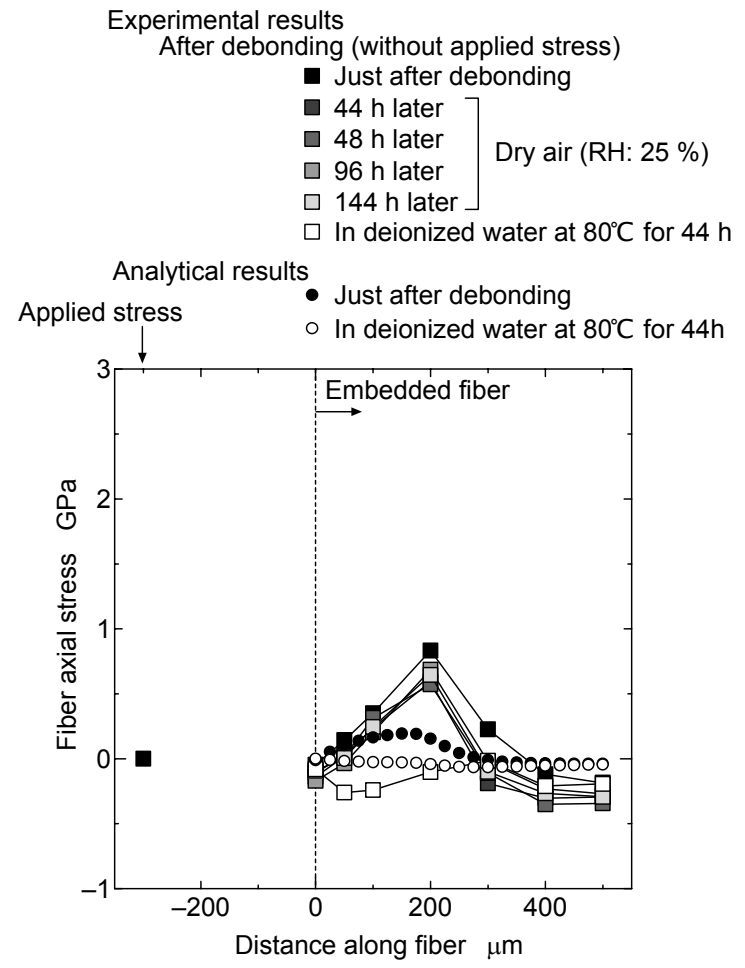

Figure 8: Influence of conditioning in dry air and successive hot water on the fiber axial stress along the fiber after debonding.

\section{Conclusions}

Stress distribution along the fiber of an Aramid fiber/epoxy model composite during the pull-out test was measured using micro-Raman spectroscopy. The stress transfer length of the fiber was about $400-500 \mu \mathrm{m}$. Although the external stress was not applied to the fiber, after the fiber/matrix interfacial debonding, the fiber in the debonded region had the residual stress caused by the holding of 
the previous stress by the fiber/matrix interfacial friction on the debonded interface. This residual stress showed the maximum at the crack tip of the interfacial debonding and the residual stress decreased to almost $0 \mathrm{GPa}$ after immersed in hot water.

\section{References}

[1] Tanaka, K., Minoshima, K. Grela W. \& Komai, K., Characterization of the Aramid/Epoxy Interfacial Properties by means of Pull-out Test and Influence of Water Absorption, Composites Science and Technology, 62(16), pp.2167-2174, 2002.

[2] Minoshima, K., Tanaka, K., Araki, Y. \& Komai, K., Characterization of the propagation of aramid/epoxy interfacial debonding under fatigue loading, JSME Mechanical Engineering Congress, Japan, No.03-1, pp.363-364, 2003.

[3] Galiotis, C. Young, R J. Yeung, P H J. \& Batchelder, D N., The Study of Model Polydiacetylene/epoxy Composites Part I The Axial Strain in the Fiber, Journal of Materials Science, 19, pp 3640-3648, 1984.

[4] Patrikis, A K. Andrews, M C. \& Young, R J., Analysis of the Single-Fiber Pull-out Test by means of Raman Spectroscopy: Part I. Pull-out of Aramid Fibers from an Epoxy Resin, Composites Science and Technology, 52, pp 387-3965, 1995.

[5] Cervenka, A J. Bannister, D J. \& Young, R J., Moisture absorption and interfacial failure in aramid/epoxy composite, Composites Part A, 29A, pp 1137-1144, 1998.

[6] Hull D. \& Clyne T.W., An Introduction to Composite Materials, Cambridge University Press, 1990.

[7] Technical paper of curing agent for Epikote resin, Japan Epoxy Resins Co. Ltd.

[8] Kawabata, S., Sera, M., Kotani, T., Katsuma, K., Niwa, M. \& Xiaoxin, C., Anisotropic Mechanical Properties of Advanced High Performance Fibers Obtained by Single Fiber Testing System, Proceedings of the Ninth International Conference on Composite Materials (ICCM/9), Madrid, 6, pp.671-677, 1993.

[9] Parthenios, J., Katerelos, D. G., Psarras, G. C. \& Galiotis, C., Arramid Fibres; a Multifunctional Sensor for Monitoring Stress/Strain Fields and Damage Development in Composite Materials, Engineering Fracture Mechanics, 69, pp.1067-1087, 2002. 